Criação / Pintura 


\title{
O Teorema de Lizárraga
}

\section{ANNATERESA FABRIS}

\begin{abstract}
ATISTA QUE transita com desenvoltura pelas manifestações da arte - uniA das entre si pela busca de uma gramática interna, na qual as idéias de 1 relação e módulo são fundamentais -, no final de 1993, Lizárraga propõe a si mesmo um desafio conceitual e visual: determinar uma área de atuação ainda mais essencial, ainda mais voltada para aquele exercício de auto-reflexão, que é o marco definidor de sua presença no panorama artístico brasileiro pósconcreto.
\end{abstract}

Sintomaticamente, essa espécie de nova aprendizagem configura-se no desenho, uma linguagem que demonstrou ser auto-suficiente ao longo de nosso século; que permitiu conferir centralidade à idéia, dissociada da vibratilidade perceptiva e existencial da matéria e da cor. O desenho, longe de ser um apontamento ou a prefiguração da obra por vir, concretiza diretamente a idéia na superfície do papel, faz vir à tona o interior da imagem, que revela em sua essencialidade estrutural, graças à transparência de um traço que não é tolhida pela densidade da matéria.

Optar pelo desenho, no caso de Lizárraga, significa optar por um processo no qual a exteriorização do trabalho do artista é ainda mais franca do que na pintura e na escultura; no qual o problema das relaçóes e da construção de formas auto-significantes se oferece com maior nitidez a uma percepção atenta e participativa.

Em seu conjunto de desenhos, Lizárraga parece ser guiado por um programa bem-definido. Um desenho pressupóe o outro: existe um conceito subjacente a todos eles, que tem na combinação e no deslocamento de elementos primários seu princípio fundamental. Na maior parte dos desenhos, o artista faz da grade a estrutura determinante da composição. É com essa superfície elementar que são construídas as diferentes topografias do conjunto, ora sujeitas a intervenções mínimas de linhas e figuras geométricas, ora pontuadas por presenças mais marcadas, que formam manchas indefinidas, mas nem por isso menos estruturadas.

Nas várias grades, a superfície transforma-se no lugar de existência e afirmação da idéia de arte de Lizárraga, alicerçada na apresentação de formas objetivas, na adesão a uma geometria pensada como estrutura primária e não como 
expressão simbólica de uma realidade exterior à operação criadora. Para evitar qualquer surpresa, o artista elabora de antemão um processo operacional preciso, graças ao qual pode ordenar seu campo de ação: relações recíprocas, deslocamentos mínimos, rebatimentos de estruturas determinam o caráter unitário do conjunto e de seus elementos definidores.

Pensada nesses termos, à operação de Lizárraga pode ser aplicada a noção de teorema, proposta por Menna para o trabalho de Lewgitt:

"c...] dada uma superfície, que implica uma série de variações sígnicas (não importa se limitadas ou infinitas), encontrar as normas operacionais necessárias para obter uma relação dos signos entre si. [...] o procedimento artístico identifica-se, enfim, com as operações transformacionais realizadas no interior do sistema e o valor da obra consiste nas modificações introduzidas no código, que o código, todavia prevê e abarca como campo de possibilidades" (1).

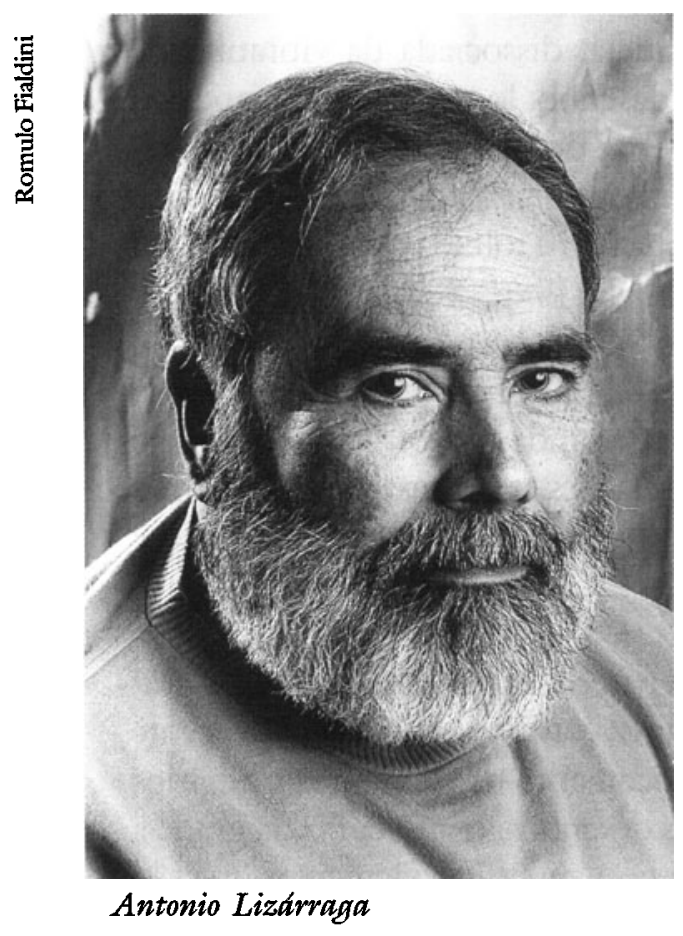

As formalizações elementares do conjunto de Lizárraga são realçadas pelo jogo de preto e branco, graças ao qual a superfície do papel dialoga com a área desenhada e com as vastas áreas vazias ou quase imperceptivelmente ocupadas por intervenções e deslocamentos mínimos.

Idéia e imagem marcam um encontro sem mediações nos desenhos de Lizárraga, nos quais os dados fundadores dessa modalidade de expressão se manifestam em sua essencialidade primeira - plano, linha, forma. Desse modo, o artista oferece ao espectador um estímulo antes mental do que simplesmente visual: perceber a operação artística como a enunciação de um teorema, na qual o sistema e as variantes possíveis remetem a uma formatividade estrutural, feita de visão e inteligência.

\section{Nota}

1 F. Menna, La linea analitica dell'arte moderna. Torino, Einaudi, 1977, p. 74-75.

Annateresa Fabris é professora titular de Teoria e História das Artes Plásticas da Escola de Comunicações e Artes da USP. 


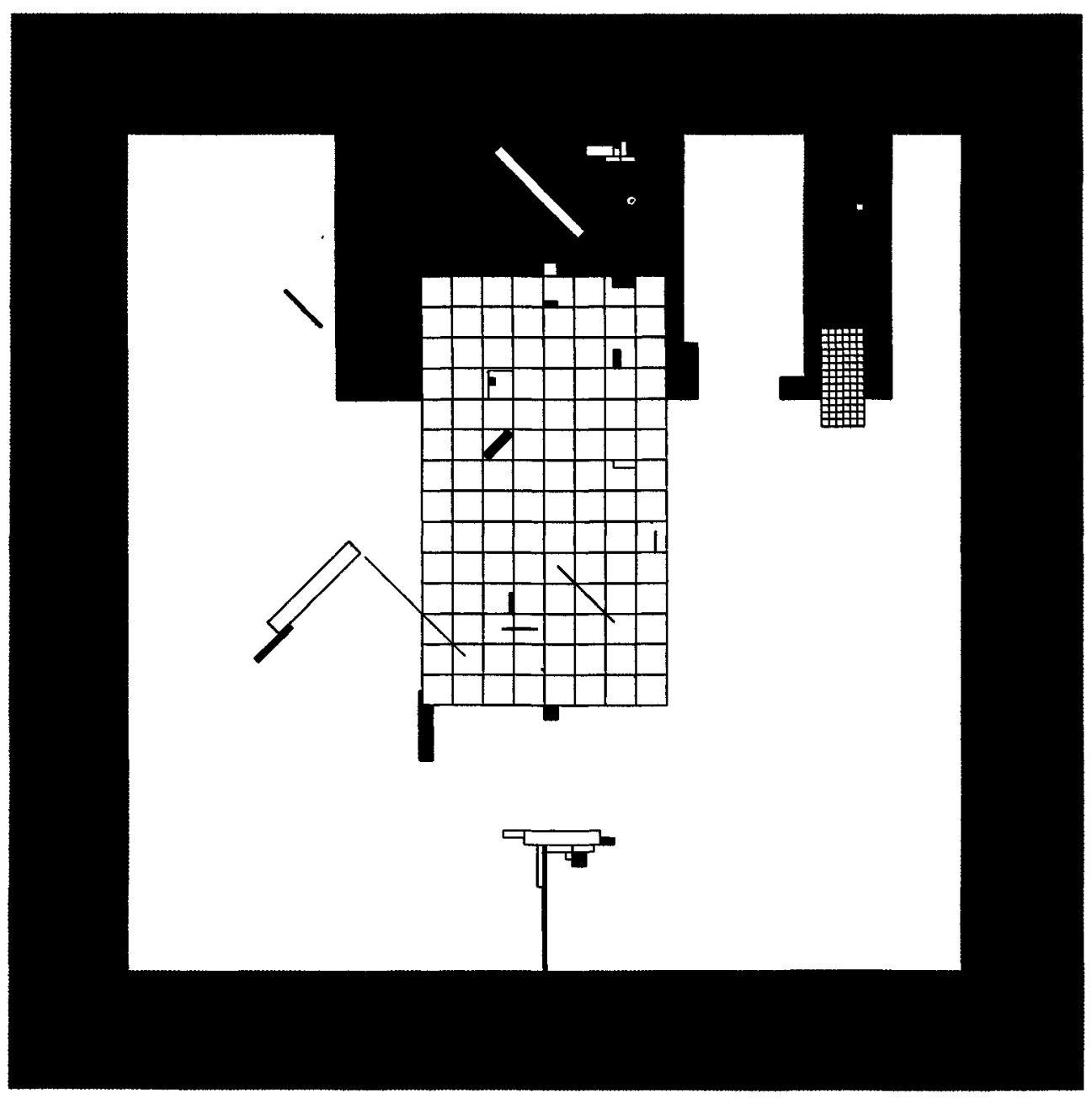




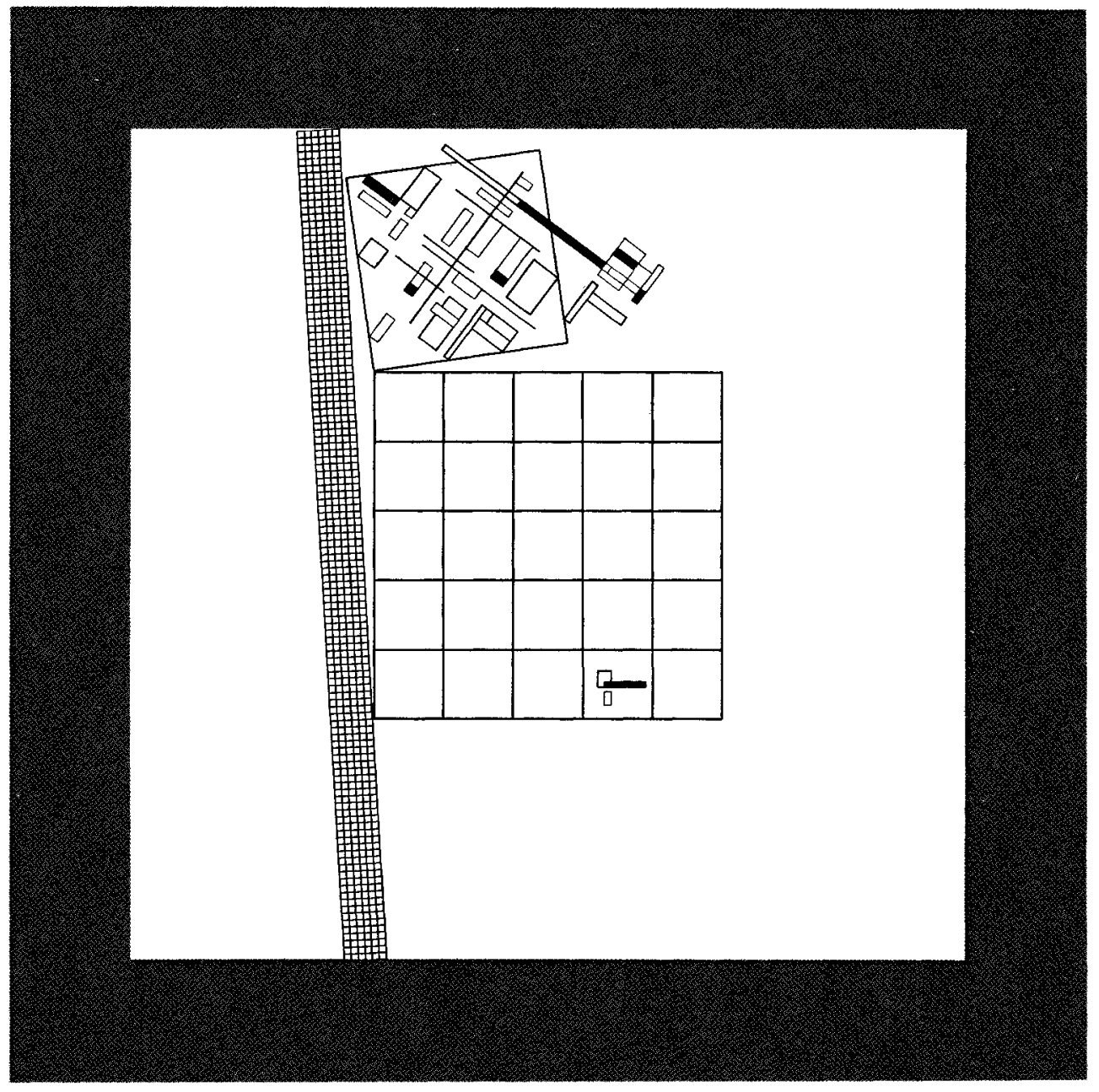




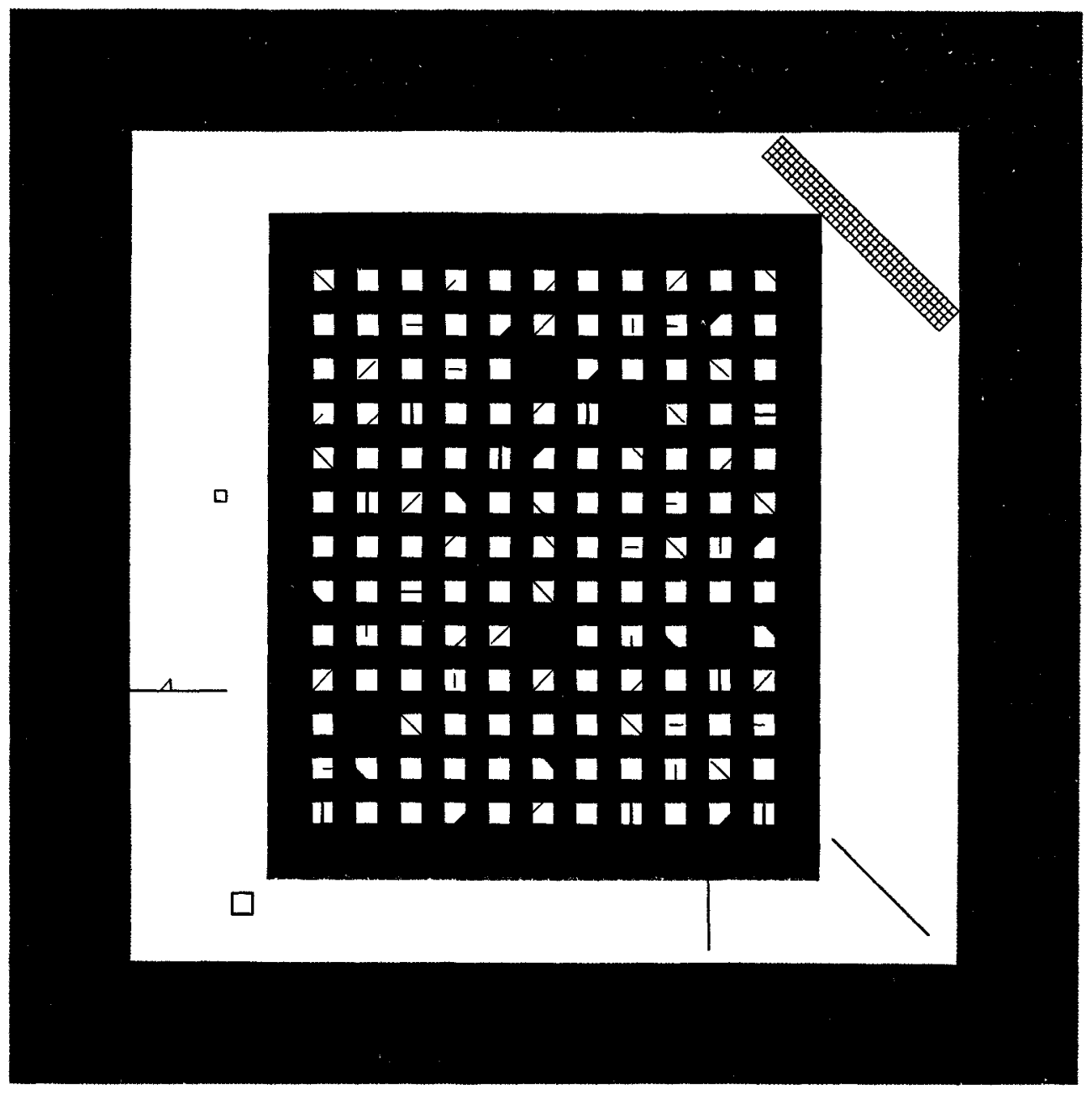




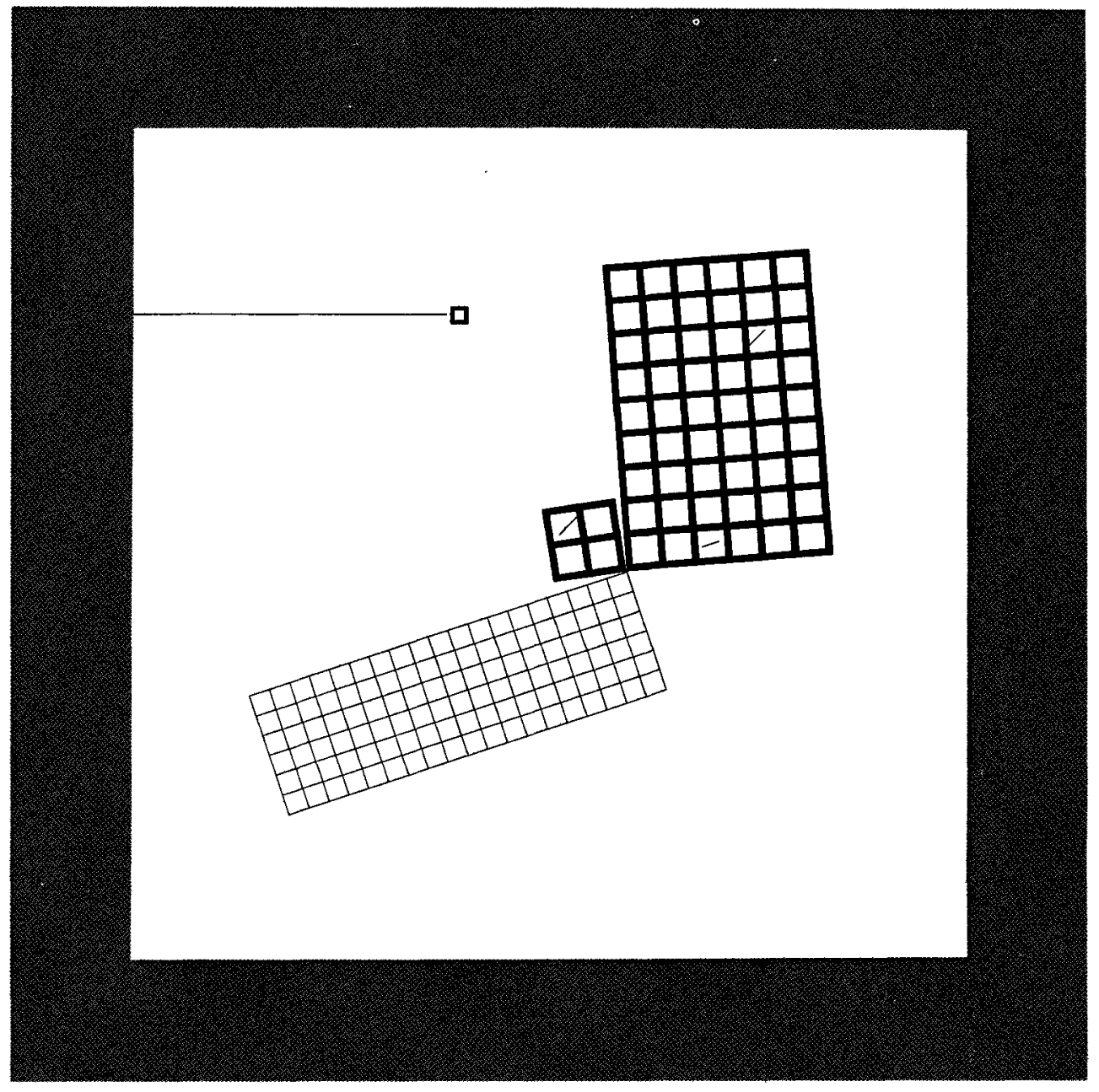




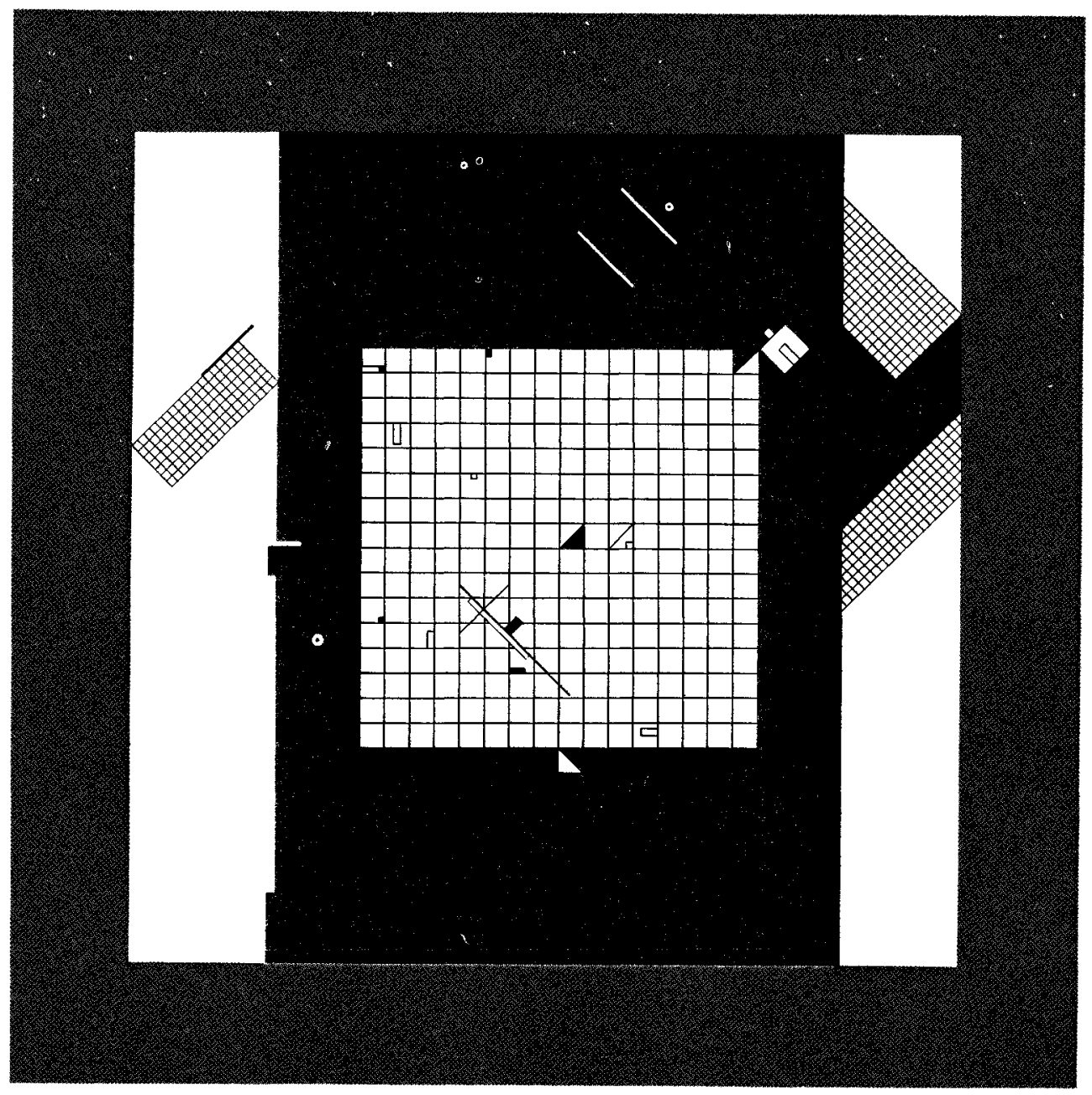

